\title{
ROLE OF A DIGITAL LAST PLANNER® SYSTEM TO ENSURING SAFE AND PRODUCTIVE WORKFORCE AND WORKFLOW IN COVID-19 PANDEMIC
}

\author{
Kevin McHugh ${ }^{1}$, Viranj Patel $^{2}$, and Bhargav Dave ${ }^{3}$
}

\begin{abstract}
To cope with the dynamics of production, construction managers spend a significant amount of time organising the workforce, managing logistics and controlling the flow. Underestimating the process of workforce allocation and management could lead to serious productivity, safety, logistics, and coordination problems. To exacerbate this situation, the onset of the global Covid-19 pandemic has created a situation where unorganised workforce allocation and tracking could increase the health and safety risk for the project. The Last Planner® System (LPS) advocates and incorporates processes to sustain flow suggested in Lean Production theory. Hence, the complex job of creating the workforce-flow can potentially be simplified through the LPS proactive planning during lookahead discussions. The paper captures a case study where the same safety and productivity issues were heavily encountered in a project involving multiple trades (15+) and having hundreds of workers struggling in the pandemic situation. Implementing design Science approach, the team has discovered a digital workflow management system that exhibits significant improvement in coordination, control over productivity wastage and safe working environment.

This research utilised a digital LPS powered by real-time cloud-based system, capable of actively tracking the agreed workforce boosting productivity whilst keeping the workforce safe and secure.
\end{abstract}

\section{KEYWORDS}

Workforce flow planning, digital, Last Planner ${ }^{\circledR}$ System, production planning and tracking.

\section{INTRODUCTION}

\section{BACKGROUND}

Safety and safe working environments are an undivided part of construction projects, yet safety management practices are often treated as separate and isolated entity in construction management (Zhang et al., 2015). Project characteristics, and complexity

Associate Director, Mace Technology, Ireland, Kevin.McHugh@macegroup.com, orcid.org/00000002-6017-4585

2 Customer Success Manager, VisiLean India Pvt. Ltd, India, viranj.patel@visilean.com, orcid.org/0000-0002-0886-874X

3 CEO, VisiLean Ltd, Finland, bhargav@ visilean.com, orcid.org/0000-0003-4228-506X 
has a significant impact on the logistics and system inhabitants. As the project complexity increases, the inherent risks with high levels of change and uncertainty are raised significantly in the project (Trinh \& Feng, 2020). With these uncontrolled dynamics of project systems, the safety hazards become inherent in the project and hence resist the flow of project delivery and productivity inevitably (Sacks et al., 2005). The overall damage to the sector is more than it has been realised only in terms of cost and delays amongst all the stakeholders (Lingard \& Rowlinson, 2005).

Over the period, countless efforts have been recorded to address the jobsite safety with people or technology (Emuze \& Smallwood, 2013). In the recent development, researchers are pushing sensor-based networking systems, computer vison, Unmanned Aerial Vehicle (UAV) and Machine Learning technologies to aid the safety assurance on construction sites (Chen et al., 2019; Fang et al., 2020; Poh et al., 2018; Seo et al., 2015; Tixier et al., 2016; Yang et al., 2020; Zhang et al., 2013). Though the detection process of the safety hazards is getting efficient, the overall development is evidently going into reactive type of safety management rather than the proactive one (Teizer et al., 2010). It emerges that there is a serious need to have a balanced review of safety management that involves people, process, product, and technology combined.

This paper initially discusses the perception of safety and how it has been connected to the production management followed by the state of the art for the same. Additionally, the state of safety due to COVID-19 pandemic has also been realised through the paper that bring about the dire need of inventing an integrated workplace safety practices which is supported by digital LPS. A case-study has been presented to capture the effectiveness and efficiency of such resilient approach.

\section{LITERATURE REVIEW}

\section{Relation Between Production Management ANd Safety}

The cognitive engineering paradigm in the research of safe working clearly states that the way groups of individuals interact with the work system has a definite impact on the safety (P. T. Mitropoulos, 2012). Hence, the way the production system is designed certainly has its implication on the overall safe working environment (Aslesen et al., 2013).

Since being suggested by several authors since the 90's, the majority of studies have investigated the integration of safety into production planning framework (Emuze \& Smallwood, 2013). Though the full-scale realisation and implementation for the same is yet to be percolated through the roots of production planning (P. T. Mitropoulos, 2012) and evidently very few researchers have captured the real-life implementation and benefits for this (Emuze \& Smallwood, 2013).

Many of the authors including (Ciribini \& Rigamonti, 1999) and (Kartam, 1995) for instance, discussed the introduction of safety measures into construction plans, using CPM or line of balance planning techniques. The CPM approach has proven quite ineffective, since it is a top-down approach that does not take into consideration reality (Koskela et al., 2014). On the other hand, collaboration focused Lean thinking suggests that the efforts undertaken to implement occupational safety and health at jobsite can be an excellent starting point to identify waste and have positive impacts for controlling the disruptions in flow (Sacks et al., 2005). Hence, the tools and techniques supported by lean concepts and principles have clear synergy and advantage of making a production management system integrated into safe working practices. For instance, (Saurin et al., 
2002) has provided safety planning and control model (SPC) where the production practices are injected within the production long/short term planning and control.

\section{StATE OF THE ART IN THE WORKFORCE SAFETY}

New tools and systems that incorporate safety protocols in the planning practices are coming to fore in recent years. For example, an investigation from Denmark (Thomassen et al., 2003) highlighted that crews using the LPS reported 45 percent fewer accidents compared to traditional management systems. The primary reason behind the decrease in accident prone safety practices has been derived from the LPS' uncompromising attitude towards high-quality work and emphasis on cyclic-collaboration activities ( $\mathrm{P}$. Mitropoulos et al., 2005). Consequently, the working conditions and workflows are fortified and the element of unpredictability in tasks which are responsible for hazardous situations, interruptions in flow and improvised processes are reduced. Nevertheless, reducing task unpredictability is only one step on the way to a safer construction site. Also important is issue management and evolving/empowering the team to successfully recognize, swiftly raise, share, cope with \& recover from hazardous situations and errors. (Aslesen et al., 2013) infer to the question yet to be answered: how we can integrate the function of error or safety management into practical production control and management.

Apart from LPS, line of balance has gained popularity in terms of maintaining the flow and promoting the safety for production. The location-based planning and line of balance combined approach is supportive for controlling process flow and operation flow simultaneously (Grau et al., 2019). The major focus here is the maintaining the flow of workforce in such a way that the safety hazards can be minimised in alignment with the process flow. Though the process-oriented safety planning appears rather effective, the implementation of the same has always been challenging with traditional approaches (Awada et al., 2016). However, combined with digitally enabled spatial awareness technologies that includes Building Information Modelling (BIM) and cloud computing, the performance of these tools in terms of managing safety can exponentially be increased (Zhang et al., 2013, 2015).

\section{Problem Statement}

The onset of the COVID-19 pandemic has forced production environments (especially in the construction domain) to become more sensitive regarding the safe working environment (Stiles et al., 2021; Wu \& Wang, 2020). The arrival of the pandemic resulted in all industrial and social activities being temporarily suspended. To successfully reopen societal and industry social distancing measures had to be implemented to safeguard the population from disease transmission. These imposed regulations have evidently posed major disruption in the production systems by restricting team's collaboration capabilities and production workflows. More specifically, office teams are now forced to work remotely which has hampered active communication resulting into coordination issues ultimately affecting the production planning. Whereas the ground teams and their numbers are strictly limited making them struggle to achieve their productivity goals. The situation demands a system where the production disruption can be kept minimum.

\section{RESEARCH METHODOLOGY}

The researchers were involved in developing and managing the project LPS and the development of the existing digital LPS. The advent of the pandemic required another iteration for the LPS. Design science research method was used to develop the hybrid digital LPS that channels the safe and remote collaboration requirements through 
production management. In the case of such complex projects, on top of safety planning a unique spatial awareness is needed to proactively determine the safety hazards on the jobsite. In order to figure out the efficiency and effectiveness of the developed solution, pre and post covid safety and production planning situations have been analysed the presented. Overall, the case study encapsulates a model workforce planning for safe and proactive production planning and management practices that has been deployed implicitly the digital LPS.

\section{CASE-STUDY}

\section{BACKGROUND}

The study was carried out on a hyperscale data centre construction project. The project is an 86,000 square meter structure consisting of 8 single storey data halls and an administration building. The project commenced early in 2019 and is expected to be completed mid-2022. The project team has matured in lean production practices and had successfully implemented the same on similar data-centre projects.

During the early first quarter of 2020, the production team has been operating almost 46,264 operative hours and roughly 895 workforces at the site.

\section{When the Pandemic Hit the Site}

In March 2020 when the production was reaching its peak, all social and industrial activity was suspended by government to reduce spread of Covid-19. After getting site-based activities suspended with only works continuing related to design and procurement. Later, when the sites were re-opened, there were many regulatory restrictions which had been introduced causing listed challenges:

- Planning, Managing, controlling number of workforces in defined area and timeframe.

- Production coordination and discussions became more difficult due to remote working and work safety distancing.

- Ensuring the volume of work is getting delivered and simultaneously avoiding the safety risks.

\section{Finding THE SOLUTION}

The team had taken up this challenge to build even more resilient and safe system of work to operate during a pandemic. This included introducing new way of visualising and analysing workforces, remote working where possible for site-based support management, additional shift patterns were introduced, and labour maximum occupancy levels were introduced on the project the maintain social distancing on the project.

In order to counter the collaboration challenges, the redeployed LPS was fully digitised which allows the teams to continue to prepare and manage the production plans despite the fragmentation of teams to mitigate Covid-19. Project based collaborative planning sessions were moved to digital meeting platforms (Microsoft ${ }^{\mathrm{TM}}$ Teams) which provided the collaborative space to work. This allowed remote working teams to come together to manage and sequence tasks. This was initially used to manage off site documentation and design work while on site activities were suspended.

As part of the return-to-work strategy the project needed to demonstrate how activities could be planned and executed while respecting social distancing. Labour management and forecasting was an important part of the return-to-work strategy. To manage this, 
maximum room occupancies were determined based on room areas to highlight allowable access to work areas. This was a further consideration for work planning process. Therefore, for tasks to be approved in the Last Planners sessions, information required was: Planned workforce, Location, Health \& safety (Distancing Method statement etc.), Quality (Tech sub, checklist inspection schedule), Quantity and Duration.

The construction team had already deployed a digital LPS system called Visilean. The Visilean team worked with the project team to solve the post covid safety challenge. In order to achieve this, new interfaces were developed in VisiLean to a) input number of planned workers in each location, b) input maximum number of workers who can be accommodated in each location while maintaining minimum safe distance, c) report number of actual workers working at each location by using the app and d) visualise and report the total number of workers at each location. Tasks now had to be assigned the properties to allow them to be sequenced and scheduled in the look ahead meetings. There was a requirement to increase the reliance on visual management to connect remote teams. This resulted in a workforce management dashboard and BIM model viewer adaption of the software to allow teams to communicate and quantify resources and outputs with declared tasks. This provided clarity for teams to support effective communication.

\section{Production Planning}

Production planning is a collaborative weekly process where meetings are held in collaborative 'Big Room'. This approach was replicated virtually to co-ordinate weekly work plans. These plans were developed on a digital platform where teams managed and co-ordinated their works (Figure 1). Preparations for the weekly workplans co-ordination meeting were held in advance and each work.

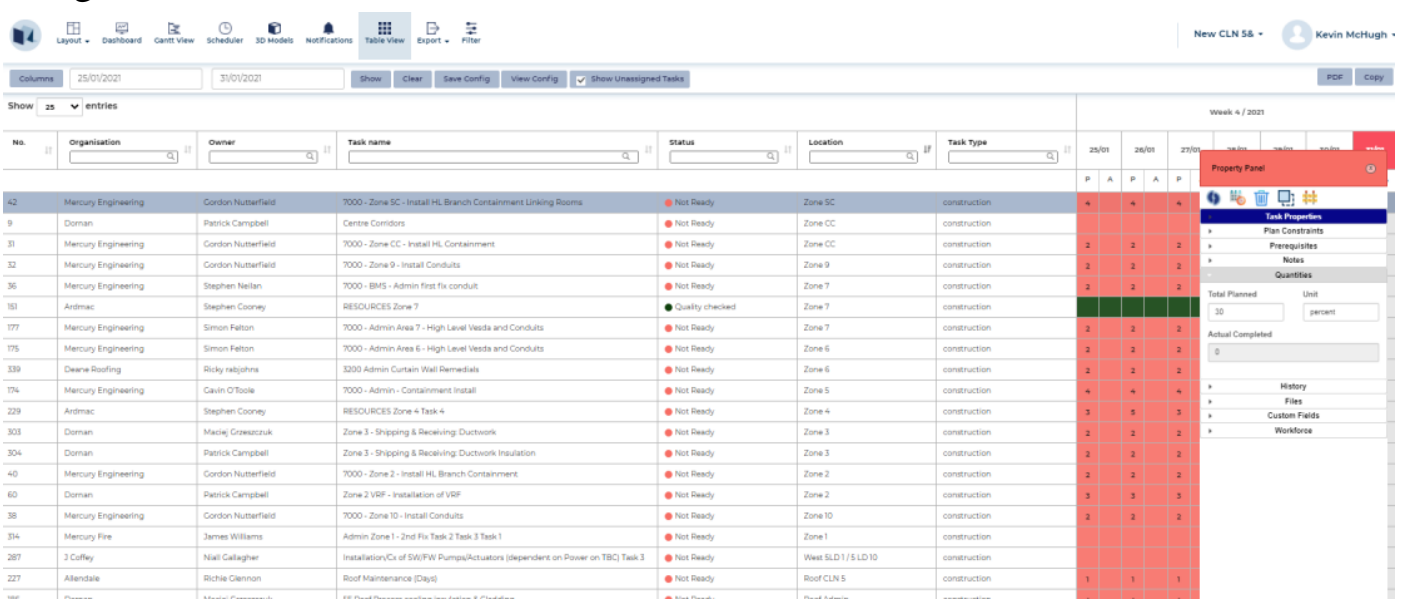

Figure 1: Digital weekly work plan

It was now needed to identify measure and control productivity while working remotely. This was done by preparing a continuity project in Visilean (Figure 2). Trade contractors were tasked to prepare and submit a 6 week look ahead for the remote working period. This resulted in more than 800 tasks being generated in the look ahead period. This assisted the team's ability to co-ordinate and manage project deliverables remotely. The teams were able to conduct package specific work plan reviews, weekly co-ordination meetings and 'Daily Activity Briefing's' (DAB's) catch up with the trade contractors while working remotely. Collaborating digitally facilitated teams to communicate and engage positively. Labour allocations were assigned based on progress updates to ensure work was available for the assigned resources. There was a focus on sequencing activities correctly to remove bottlenecks \& ensure operatives can safely work together in an area. 


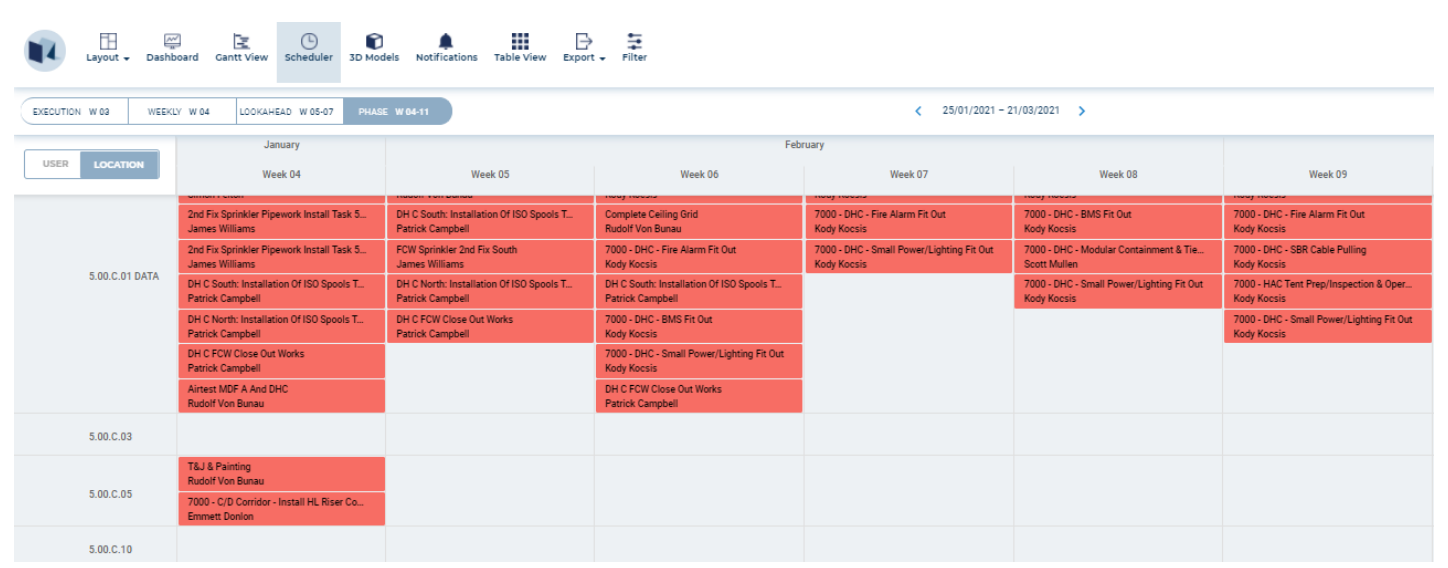

Figure 2: Digital pull plan session

With this structure in place the production management crew were able to maintain effective communication with the operation teams and work collectively to deliver value to the client. The teams were also able to demonstrate this by sharing the planned and actual production.

\section{Production Control}

The requirement to manage the production control system digitally was now essential to manage the development and delivery of weekly work plans. It was evident that during covid-19, the production process would need to be amended. to help forecast labour allocations. There was also an increased importance of resource forecasting and management. There was a requirement to measure planned and actual daily workforce and a requirement to control how they were deployed.

An amended project plan was developed to operate during the pandemic. This plan was resourced based on maximum project occupancy levels and was divided into shifts to mitigate bottlenecks and maintain productivity to achieve existing project milestones.

The resource loading of plans was required to plan works in each project area (Figure 3). All rooms were assigned a maximum allowable personnel capacity based on its floor area. This assisted the sequencing of works, where the teams could identify if they can complete the works in the original timeframe or introduce mitigation methods. Plans were communicated and controlled using DAB's meeting that were held on the floorplate and hosted online to allow increased engagement and transparency. Tasks were updated daily with actual resource numbers assigned to tasks to ensure works have been accounted for. The workforce could then be managed efficiently by project supervisor and that no overcrowding of work areas occurred.

This led to a greater emphasis for the creation of weekly work plans. The previous study (McHugh et al., 2019) identified areas for improvement using PPC as a tool for measuring reliability the focus was on constraint removal $\&$ accurately sizing work for weekly outputs. There was also an increased focus on the quantities of work declared to allow to improve the predictability of completed sections of work. At the DAB's meetings, the activities were declared by the supervisors and updated on the platform using the mobile application in the field to ensure all activities were identified. All work should have safety, design, logistics and personnel constraints removed before committing to weekly tasks. This facilitated supervisors to focus on site co-ordination which improved the quality of commitments a highlighted the interdependencies of trades in the field.

The use of the digital platform assisted the resource to be sequencing which improved the detail in the look ahead to process. Trade contractors could work on their look ahead 
plans with full visibility of current constrains and current look ahead plans. Trade contractors could then issue their look ahead plans in line with preceding works which could highlight risks and opportunities to the construction delivery programme. This level of preparation of look ahead planning, constraint analysis and quantified weekly work plans that were created in a digital platform was a rich source of information. This enabled teams to gather fully informed and prepared for weekly co-ordination meetings. This provided a greater level of detail for discussion to allow teams to manage a large volume of tasks in the weekly meeting.

The digitised LPS provided a greater connection between all levels of site management and operatives. The ability of trade contractors to manage their tasks and resources improved this connection. Risks were easily highlighted and mitigating works could be co-ordinated to manage at risks areas. Opportunities for improvement could be managed by bringing forward design coordination, procurement of materials and mobilising resources to match the improved production rates.

\begin{tabular}{|c|c|c|c|c|c|c|c|c|}
\hline Location & Daily Limit & $\underset{\text { sum }}{\text { Th/ }}$ & $\underset{\text { MON }}{18 / h}$ & $\begin{array}{l}19 / 1 \\
\text { TUE }\end{array}$ & $\underset{\text { wED }}{20 / h}$ & $\begin{array}{l}21 / 1 \\
\text { тнU }\end{array}$ & $22 / 1$ & $\underset{S A T}{23 A}$ \\
\hline 5.00.M.15 ADMIN PLANTROOM Tasks & 2 & 0 & 0 & 0 & 0 & 0 & 0 & 0 \\
\hline 5.00.M.12 ELECTRICAL ROOM Tasks & 2 & 0 & 0 & 6 & 6 & 6 & 6 & 0 \\
\hline 5.00.M.09 S/R SECURITY Tasks & 2 & 0 & 2 & 0 & 0 & 0 & 0 & 0 \\
\hline 5.00.M.08 BOH ENTRY VESTIBULE TaskS & 2 & 0 & 0 & 0 & 0 & 0 & 0 & 0 \\
\hline 5.00.M.07 SECURITY OFFICE Tasks & 2 & 0 & 0 & 0 & 0 & 0 & 0 & 0 \\
\hline 5.00.M. $06 \mathrm{SOC} \mathrm{A} / \mathrm{V}$ Tasks & 2 & 0 & 0 & 0 & 0 & 0 & 0 & 0 \\
\hline 5.00.M.05 SECURITY STORAGE Tasks & 2 & 0 & 0 & 0 & 0 & 0 & 0 & 0 \\
\hline 5.00.M.04 SOC Tasks & 2 & 0 & 0 & 0 & 0 & 0 & 0 & 0 \\
\hline 5.00.M.01 BATTERY STORAGE Tasks & 2 & 0 & 4 & 4 & 6 & 4 & 2 & 0 \\
\hline - Zone SC Tasks & - & 0 & 4 & 4 & 4 & 4 & 4 & 0 \\
\hline 5.00.M.02 HALLWAY Tasks & 2 & 0 & 2 & 0 & 0 & 0 & 0 & 0 \\
\hline - Zone 2 Tasks & - & 0 & 4 & 4 & 4 & 4 & 4 & 0 \\
\hline
\end{tabular}

Figure 3: Workforce room occupancy management dashboard.
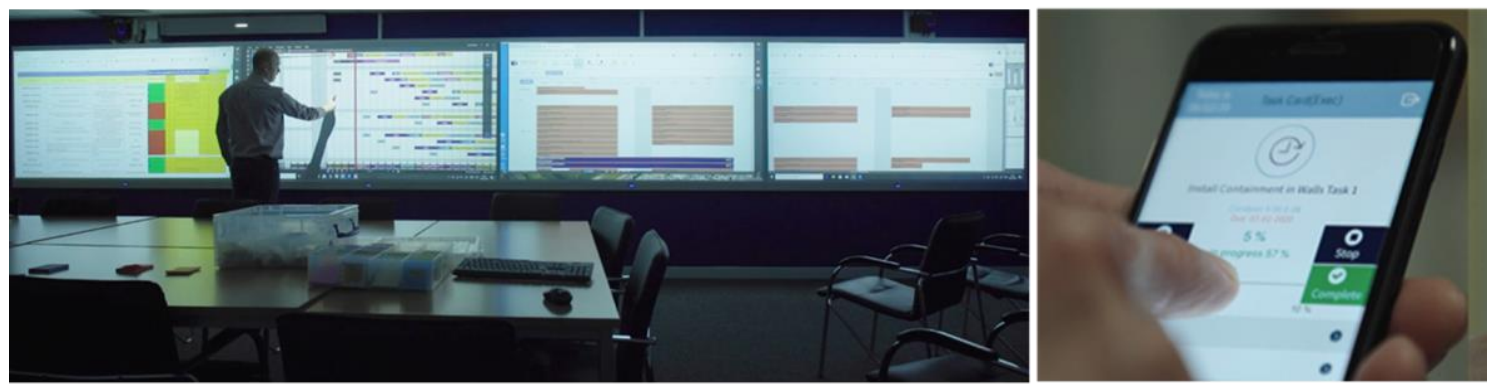

Figure 4: Digital workflow for managing the production environment.

The use of the mobile application (Figure 4) that provided greater control from the trade supervisors to manage works in the field. This also supported supervisors to identify works which were not fully identified in current weekly work plans that could be added to improve the detail of future submitted weekly work plans. The use of the mobile app in the field improved the accuracy of reporting and improved the quality of the collaboration which was based on the latest information from the field. The Dab's discussions were more informed and the high activity areas could be broken down into 
more manageable work zones. Management could then provide the support needed to maintain progress \& ensure targeted areas were open for production free of constraints.

\section{DISCUSSION}

The daily workforce check-in at the DAB's is an essential component of the LPS. Trade contractors can confirm activities are in progress and highlight risks and opportunities related to their tasks. This provides an opportunity for improving the trade-to-trade handovers and increasing the quality of planned assignments. The quality of the information assigned to each activity facilitated greater coordination between project teams. Resources could be managed where social distancing could be achieved and improved interaction between trades improved the sequencing of subsequent works.

Digitising the weekly planning provided greater transparency between teams which increased the engagement with the production control system All trades had access to each other's plans and could review and discuss planned works and highlight dependencies and risks to each other. This provided greater information and allowed contractors to communicate effectively. This improved quality of information provided a safer working environment. The development and focus of labour resource reporting was identified as key constraint for operating during a pandemic. The authors developed a workforce management function in the existing digital LPS.

This update has established strong basis of discussion that has elevated safety discussion from operational to tactical level proceedings. Moreover, Production level safety discussions are now percolating to the ground level team in form of mandatory (digitally) prerequisites that cannot be missed reducing the scope of ambiguity.

\section{OUTLINING THE Future State}

More and more projects will adapt lean construction techniques to improve project productivity and hance would be needing safe ways of effective collaboration. Ultimately, the ability to plan safety, collaborate, react, and manage production plans in the pandemic situation by more advance mediums i.e., using a combination of sensory and imagery data has become more vital to increase the spatial and situational awareness. In a nutshell, the objective is to reinforce the collaborations systems and channels with by enabling safe working planning and control platforms where teams can plan, assess, and ensure the safety proactively. By providing a strong link between fragmented project teams a greater awareness and understanding can be developed where teams can be more productive and increase the safety and quality of construction tasks.

\section{CONCLUSION}

The LPS has proven to be robust and provided a basis for improving the production control system for managing a construction project during the pandemic. A new constraint was recognised where personnel had to maintain safe working distance. Access and logistical measures were also put in place to increase the control of personnel and materials. The digitisation of the LPS allowed teams to fully integrate despite further fragmentation. Teams were no longer permitted to gather in a 'big room' to collaborate and socially interact with each other, or to come together at the workplace and interact at daily activity briefings. Digitising the LPS supported the team's ability to interact remotely and provided the social aspect that was reduced through social distancing by sharing all information on one platform, enhancing communication and collaboration. Digitising the LPS fully integrated project teams and improved the quality of the 
interactions. This can be further developed in a post pandemic world \& add real value to construction production processes.

The digitised LPS will be used in future post pandemic operations. The greater connectivity between site \& office-based personnel increased engagement with the LPS. Greater team visibility improved the quality of the WWP's. This improved the size \& sequencing of planned works. This has provided a greater safety, quality, and more efficient assignments. An average 1100 operative working a cumulative of 57,000 operative hours recorded are being managed collaboratively using the Digital LPS.

\section{REFERENCES}

Aslesen, S., Sandberg, E., Stake, S., \& Bølviken, T. (2013). Integrating safety analyses in production planning and control - a proposal. Iglc-21, 4, 843-852.

Awada, M. A., Lakkis, B. S., Doughan, A. R., \& Hamzeh, F. R. (2016). Influence of Lean Concepts on Safety in the Lebanese Construction Industry. International Group for Lean Construction, 11, 63-72.

Chen, Y., Zhang, J., \& Min, B. C. (2019). Applications of BIM and UAV to construction safety. Proceedings, Annual Conference - Canadian Society for Civil Engineering, 2019-June, 1-7.

Ciribini, A., \& Rigamonti, G. (1999). Time/Space chart drawings techniques for safety managemen. Proceedings of International Conference of CIB Working Commission W99, 25-32.

Emuze, F., \& Smallwood, J. (2013). The integration of health and safety (H\&S), lean and sustainability in construction: A literature review. 21st Annual Conference of the International Group for Lean Construction 2013, IGLC 2013, 051, 736-745.

Fang, W., Ding, L., Love, P. E. D., Luo, H., Li, H., Peña-Mora, F., Zhong, B., \& Zhou, C. (2020). Computer vision applications in construction safety assurance. Automation in Construction, 110 (November 2019), 103013. doi.org/10.1016/j.autcon.2019.103013.

Grau, D., Abbaszadegan, A., \& Assanair, R. (2019). Process versus operations workflow - Making the case for continuous monitoring of construction operations. 27th Annual Conference of the International Group for Lean Construction, IGLC 2019, 1, 563572. doi.org/10.24928/2019/0197.

Kartam, N. (1995). Integrating construction safety and health performance into CPM. ASCE Construction Congress Proceedings, June, 456-462.

Koskela, L., Howell, G., Pikas, E., \& Dave, B. (2014). If CPM is so bad, why have we been using it so long? 22nd Annual Conference of the International Group for Lean Construction: Understanding and Improving Project Based Production, IGLC 2014, $27-37$.

Lingard, H., \& Rowlinson, S. (2005). Occupational Health and Safety in Construction Project Management. In H. Lingard \& S. Rowlinson (Eds.), Spon Press (2005th ed.). Spon Press Taylor \& Francis Group.

McHugh, K., Dave, B., \& Craig, R. (2019). Integrated lean and BIM processes for modularised construction - A case study. 27th Annual Conference of the International Group for Lean Construction, IGLC 2019, 227-238. doi.org/10.24928/2019/0252.

Mitropoulos, P., Abdelhamid, T. S., \& Howell, G. A. (2005). Systems Model of Construction Accident Causation. Journal of Construction Engineering and Management, 131(7), 816-825. $\quad$ doi.org/10.1061/(ASCE)07339364(2005)131:7(816). 
Mitropoulos, P. T. (2012). Production control and safety management as project safety determinants. IGLC 2012 - 20th Conference of the International Group for Lean Construction.

Poh, C. Q. X., Ubeynarayana, C. U., \& Goh, Y. M. (2018). Safety leading indicators for construction sites: A machine learning approach. Automation in Construction, 93(March), 375-386. doi.org/10.1016/j.autcon.2018.03.022.

Sacks, R., Rosenfeld, Y., \& Rozenfeld, O. (2005). Lean scheduling for safety: Development of a time-dependent risk level model. Proceedings of the 13th International Group for Lean Construction Annual Conference, 513.

Saurin, T. A., Formoso, C. T., Cambraia, F. B., \& Howell, G. (2002). A Cognitive Systems Engineering Perspective of Construction Safety. Safety, Quality and Environmental Management Systems.

Seo, J., Han, S., Lee, S., \& Kim, H. (2015). Computer vision techniques for construction safety and health monitoring. Advanced Engineering Informatics, 29(2), 239-251. doi.org/10.1016/j.aei.2015.02.001.

Stiles, S., Golightly, D., \& Ryan, B. (2021). Impact of COVID - 19 on health and safety in the construction sector. October 2020. doi.org/10.1002/hfm.20882.

Teizer, J., Allread, B. S., Fullerton, C. E., \& Hinze, J. (2010). Autonomous pro-active real-time construction worker and equipment operator proximity safety alert system. Automation in Construction, 19(5), 630-640. doi.org/10.1016/j.autcon.2010.02.009.

Thomassen, M. A., Sander, D., Barnes, K. A., \& Nielsen, A. (2003). Experience and results from implementing lean construction in a large Danish contracting firm. Proceedings of 11th Annual Conference on Lean Construction, 644-655.

Tixier, A. J. P., Hallowell, M. R., Rajagopalan, B., \& Bowman, D. (2016). Application of machine learning to construction injury prediction. Automation in Construction, 69, 102-114. doi.org/10.1016/j.autcon.2016.05.016.

Trinh, M. T., \& Feng, Y. (2020). Impact of Project Complexity on Construction Safety Performance: Moderating Role of Resilient Safety Culture. Journal of Construction Engineering and Management, 146(2), 04019103. doi.org/10.1061/(ASCE)CO.19437862.0001758 .

$\mathrm{Wu}, \mathrm{X} .$, \& Wang, Y. (2020). Research on the construction of government emergency management system under the "COVID-19" 2(4), 41-52. https://francispress.com/uploads/papers/0dK9ppxTnlKZRmpGrTFgM6tWpKrzY2W41qQeacNz.p df.

Yang, R. J., Gunarathna, C. L., McDermott, V., Lingard, H., Zhao, H., \& Liu, C. (2020). Opportunities for improving construction health and safety using real-time $\mathrm{H} \& \mathrm{~S}$ management innovations: a socio-technical-economic perspective. International Journal of Construction Management, 20(5), 534-554. doi.org/10.1080/15623599.2018.1490866.

Zhang, S., Sulankivi, K., Kiviniemi, M., Romo, I., Eastman, C. M., \& Teizer, J. (2015). BIM-based fall hazard identification and prevention in construction safety planning. Safety Science, 72, 31-45. doi.org/10.1016/j.ssci.2014.08.001.

Zhang, S., Teizer, J., Lee, J. K., Eastman, C. M., \& Venugopal, M. (2013). Building Information Modeling (BIM) and Safety: Automatic Safety Checking of Construction Models and Schedules. Automation in Construction, 29, 183-195. 